\title{
Effects of alpha, beta momorcharin fruit extract with the combination of Cyclophosphamide in the treatment of glioma cancer In-vivo
}

\author{
Gunasekar Manoharan $1{ }^{*}$ and Bhargava Gottam ${ }^{2}$ \\ ${ }^{1}$ New Jersey Bioscience Centre, 675 US Highway 1, North Brunswick, New Jersey, USA. \\ ${ }^{2}$ Harrisburg University of Science and Technology, Pennsylvania, USA.
}

International Journal of Biological and Pharmaceutical Sciences Archive, 2021, 02(01), 151-156

Publication history: Received on 01 August 2021; revised on 08 September 2021; accepted on 10 September 2021

Article DOI: https://doi.org/10.53771/ijbpsa.2021.2.1.0078

\begin{abstract}
The vegetable Momordica charantia L., (family: Cucurbitaceae) is a scientific name of the plant and its fruit. It is also known by other names, for instance in the USA it is known as Bitter gourd or balsam pear while it's referred to as the African cucumber in many African countries. M. charantia is believed to posse's anti-carcinogenic properties and it can modulate its effect via xenobiotic metabolism and oxidative stress. This study was specifically designed to investigate the cellular mechanisms whereby $\alpha, \beta$ momorcharin an extract of $M$. charantia can induce cell death with the combination of Cyclophosphamide. Different concentration $(200 \mu \mathrm{M}-1000 \mu \mathrm{M})$ of the $\alpha, \beta$ momorcharin fruit extract were treated ( $24 \mathrm{hrs}$ incubation) separately with three different cancer cell lines 1321N1, Gos-3, U87-MG and normal L6 muscle cell line. The results also show that Cyclophosphamide $(250 \mu \mathrm{g})$ with $(1000 \mu \mathrm{M})$ of the $\alpha, \beta$ momorcharin extract of $M$. charantia, and result in significant decreases in cell viability for each cell line, these effects were additive compared to the individual effect of Cyclophosphamide.
\end{abstract}

Keywords: Cancer cell lines; $\alpha$ momorcharin; $\beta$ momorcharin extract of $M$. charantia; Cyclophosphamide (CYP)

\section{Introduction}

The water-soluble extract of the $M$. charantia can significantly reduce blood glucose concentrations in type- 1 diabetic rats [1-2]. Several studies have reported that the water-soluble extract of $M$. charantia can exert anti-cancerous activity through inhibition of DNA, RNA and cellular protein synthesis [3-7]. The fruit juice of M. charantia has been found to increase glucose up take by several tissues in vitro and moreover, it can increase the storage of glycogen by the liver [810]. Cyclophosphamide (CP) is an alkylating agent and is usually administrated orally or intravenously and much less frequently intramuscularly or intraperitoneally [11-14]. CP is hydrolyzed in the liver by cytochrome enzymes P450 to the active form 4-hydroxyclophosphamide, which can diffuse out into circulation and affects the target cells [14-18]. In the cytosol of cell, through spontaneous $\beta$-elimination, acrolein and phosphoramide mustard evolve [19-21]. These are the actual agents responsible for cytotoxic effects and DNA crosslinking [22-23].

\section{Material and methods}

\subsection{Extraction method for either of $\alpha$ or $\beta$ momorcharin}

The whole fruit of bitter gourd was ground and homogenized in 2 mM sodium phosphate buffer, pH 7.5. The resulting slurry was then stirred for 3 hrs to extract the crude proteins. The insoluble component from crude proteins was removed by the filtration and centrifugation at $30,000 \mathrm{x}$ g for 1 hour at $48^{\circ} \mathrm{C}$. By using $2 \mathrm{mM}$ sodium phosphate buffer,

\footnotetext{
* Corresponding author: Gunasekar Manoharan

New Jersey Bioscience Centre, 675 US Highway 1, North Brunswick, New Jersey, USA.

Copyright (C) 2021 Author(s) retain the copyright of this article. This article is published under the terms of the Creative Commons Attribution Liscense 4.0.
} 
pH 7.5, the crude protein solution was dialyzed. The dialyzed protein sample was applied to DEAE Sepharose column equilibrated with $2 \mathrm{mM}$ sodium phosphate buffer at $\mathrm{pH}$ 7.5. The unbound proteins were then applied to Mono-S column which was equilibrated by $2 \mathrm{mM}$ sodium phosphate buffer at $\mathrm{pH} 7.5$ and eluted by $0.5 \mathrm{~m}$ of $\mathrm{NaCl}$. The fraction corresponding to either $\alpha$ and $\beta$ or $\alpha, \beta$ momorcharin, which was confirmed the N-glycoside activity RNA, was concentrated and dialyzed against $20 \mathrm{mM}$ Tris-HCl buffer, $\mathrm{pH}$ 7.8. The chromatography was performed on Bio Logic DuoFlow system (BioRad, Hercules, CA) at $48^{\circ} \mathrm{C}$. The purity of $\alpha$ and $\beta$ momorcharin was examined by SDS-PAGE and gel filtration chromatography. The concentration of $\alpha$ - momorcharin was determined by spectrophotometrically using optical absorbance at $280 \mathrm{~nm}$.

\subsection{Passaging of the Cancer cell lines and Control cell line}

The culture medium, phosphate buffer solution (PBS), and trypsin (sterile) were removed from the fridge at $4^{\circ} \mathrm{C}$ and subsequently placed in the water bath at $37^{\circ} \mathrm{C}$ for $30 \mathrm{~min}$ in order to equilibrate. The Laminar flow hood was turned on for $15 \mathrm{~min}$, prior to start of the experiment, in order to purge the air inside the cabinet and to reach the maximum cleanliness.

The different cancer 1321N1, Gos-3, U87-MG and L6 muscle normal cell lines were incubated at $37^{\circ} \mathrm{C}$ incubator in an atmosphere of $5 \% \mathrm{CO}_{2}$ in air. The cells were examined under the inverted contrast microscope to note the both confluence and general health of the cells. The flask was passaged when the cells had reached 70-80\% confluence. The medium was aspirated from the cultured flask and was washed with sterile PBS $\left(5 \mathrm{ml}\right.$ if $75 \mathrm{~cm}^{2} \mathrm{flask}$ and $2 \mathrm{ml}$ if $25 \mathrm{~cm}{ }^{2}$ flask) in order to remove any traces of serum from the cells. This prevented the serum from inactivating the trypsin, which was used to detach adherent cells from the cell clump. Trypsin solution $\left(2 \mathrm{ml}\right.$ if $75 \mathrm{~cm}^{2} \mathrm{flask}$ or $1 \mathrm{ml}$ if $25 \mathrm{~cm}{ }^{2}$ flask) was pipetted in the flask and incubated at $37^{\circ} \mathrm{C}$ in an incubator in an atmosphere of $5 \% \mathrm{CO}_{2}$ in air for $3-5$ mins until the cells began to detach. The detachment was confirmed by observing at intervals under an inverted microscope. The cells were left in the trypsin solution for the correct length of time. If the cells were left for a longer period of time, then this would lead to damage of the cells. A volume of $3 \mathrm{ml}$ complete growth medium was then added to the flask to inactivate the trypsin and the cells were pipetted up and down to break up any large cell aggregates. The cell suspension was transferred from flask into $15 \mathrm{ml}$ centrifuge tube and centrifuged at $1000 \mathrm{rpm}$ for $5 \mathrm{~min}$. Following centrifugation, the supernatant was aspirated and the cells were pellet at the bottom of the centrifuge tube. Based upon the cell pellet density volumes of $1 \mathrm{ml}$ to $3 \mathrm{ml}$ fresh medium were suspended in the centrifuge tube. The cell pellet was flicked properly in the medium containing $20 \mu \mathrm{l}$ of trypsinised cell suspension and $80 \mu \mathrm{l}$ of tryphan blue (used to detect dead cells in the cell suspension 1:5 ratio). The contents were mixed well together and a haemocytometer test was performed using 1 $\mathrm{ml}$ of cell suspensions. This process helped to assess the total number of the cell suspension present in the centrifuge tube and which was required to make 1 or 2 flasks and to do 96 well plates. Thereafter, the cells were frozen in liquid nitrogen depending on the number of cells present per ml. The cell suspension was divided in either one or several flasks (depending on the cell density) and fresh growth medium (10 ml to $12 \mathrm{ml}$ if $75 \mathrm{~cm}^{2}$ flask and $5 \mathrm{ml}$ if $25 \mathrm{~cm} \mathrm{flask}^{2}$ was added to the flasks. These were then placed in a $5 \% \mathrm{CO}_{2}$ incubation.

\subsection{Preparation and application of $\alpha, \beta$ momorcharin extracts of $M$. charantia on the cancer and L6 cell lines.}

Amounts of $14.51 \mathrm{mg}, 29.25 \mathrm{mg}, 43.53 \mathrm{mg}, 58.50 \mathrm{mg}$, and $72.57 \mathrm{mg}$ of either $\alpha$ or $\beta$ momorcharin and $\alpha, \beta$ momorcharin $(9.7 \mathrm{kDa})$ were weighed out separately in $5 \mathrm{ml}$ universal vials and initially dissolved in $500 \mu$ of phosphate buffer by continuous stirring and with the brief use of a sonicator water bath. These were then made up to $5 \mathrm{ml}$ by adding $4.5 \mathrm{ml}$ of the cell medium to give concentrations $200 \mu \mathrm{M}, 400 \mu \mathrm{M}, 600 \mu \mathrm{M}, 800 \mu \mathrm{M}, 1000 \mu \mathrm{M}$, respectively. The drug (extract) stock solution was transferred to a $10 \mathrm{ml}$ syringe and sterile filtered using $0.22 \mu \mathrm{m}$ filters into another sterile $10 \mathrm{ml}$ Universal bottles. These stock solutions were stored in a sealed tube in the fridge until required. Once removed from the fridge the prepared drug (extract) solutions were gently warmed in water bath at $37^{\circ} \mathrm{C}$ in order to ensure that the $\alpha, \beta$ momorcharin was in a complete solution, before aliquoting. Volumes of $40 \mu \mathrm{l}, 80 \mu \mathrm{l}, 120 \mu \mathrm{l}, 160 \mu \mathrm{l}, 200 \mu \mathrm{l}$ contained $200 \mu \mathrm{M}, 400 \mu \mathrm{M}, 600 \mu \mathrm{M}, 800 \mu \mathrm{M}, 1000 \mu \mathrm{M}$, respectively. Different concentrations of $\alpha, \beta$ momorcharin were transferred in triplicate using a Gilson pipette to 96 wells plate and the volume made to $200 \mu$ l by adding the cell media to both treated and control cell wells. Both control (untreated) and treated with ( $\alpha, \beta$ momorcharin) 96 well plates were incubated for $24 \mathrm{hrs}$.

\subsection{Dose dependent effects of Cyclophosphamide on cancer cell line viability}

In this series of experiments, different cancer cell lines (1231N1, Gos-3, U87-MG) and healthy L6 muscle cell line were incubated with the different concentrations of Cyclophosphamide (50 - $250 \mu \mathrm{g}$ ) for 24 hours. Control cell lines were also incubated for the same period of time but without any Cyclophosphamide. At the end of the incubation period, cell viability of each cell line was measured using the MTS assay. 


\subsection{Combined effects of either Cyclophosphamide with the $\alpha, \beta$ momorcharin extract of $M$. charantia}

Different cancer cell lines (1231N1, Gos-3, U87-MG) and healthy L6 muscle cell line was incubated either with Cyclophosphamide $(250 \mu \mathrm{g})$ and the $\alpha, \beta$ momorcharin extract of $M$. charantia $(1000 \mu \mathrm{M})$ or Cyclophosphamide $(250$ $\mu \mathrm{g}$ ) and $1000 \mu \mathrm{M}$ ) of the $\alpha, \beta$ momorcharin for 24 hours. Control cell lines were also incubated for the same time but without any drug or extract. At the end of the incubation period, cell viability of each cell line was measured using the MTS assay.

\subsection{Statistical Analysis}

All control and test data collected from the different experiments were analysed using Statistical Package for Social Sciences (SPSS) version 17, Student's t- test and ANOVA test. Data obtained were expressed as mean \pm standard deviation (S.D). Each experiment was repeated for 4-6 times in duplicate ( 6 for cell viability and 4 for cell signalling) to ensure the accuracy of results. A value of $(\mathrm{p}<0.05)$ was taken as significant.

\section{Results and discussion}

\subsection{Dose-dependent effects of Cyclophosphamide on cell viability}

Figure 1 shows the effects of different concentrations $(50-250 \mu \mathrm{g})$ of Cyclophosphamide on the viability of the three different cancer cell lines and on healthy L6 skeletal muscle cell line employed in this study. Also shown in the figure 1 are the untreated three different cancer cell lines and healthy L6 skeletal muscle cell line for comparison. All the cells were treated with Cyclophosphamide for 24 hours. Each control cell lines were also incubated for 24 hrs but with no Cyclophosphamide. The results show that in all three different cancer cell lines (1321N1, Gos-3, U87-MG), Cyclophosphamide can evoke marked and significant $(\mathrm{p}<0.05)$ decreases in the cell viability (cell death) compared to untreated cells (100\% viability). These effects of the Cyclophosphamide were dose-dependent with maximal cell death occurring with $250 \mu \mathrm{g}$. Similarly, Cyclophosphamide significantly $(\mathrm{p}<0.05)$ decreased the viability of healthy L6 skeletal muscle cell line compared to untreated L6 cell line but mainly at a high dose. The results also show that Cyclophosphamide was more effective in killing 1321N1 and Gos-3, cell lines. It has less effective on U87-MG cell line, which seems to be more resistant to the drug. The surprised finding in this study was that Cyclophosphamide could also kill healthy L6 skeletal muscle cell compared to the $\alpha, \beta$ momorcharin extract of $M$. charantia, which had less effect on the viability of L6 cell line.

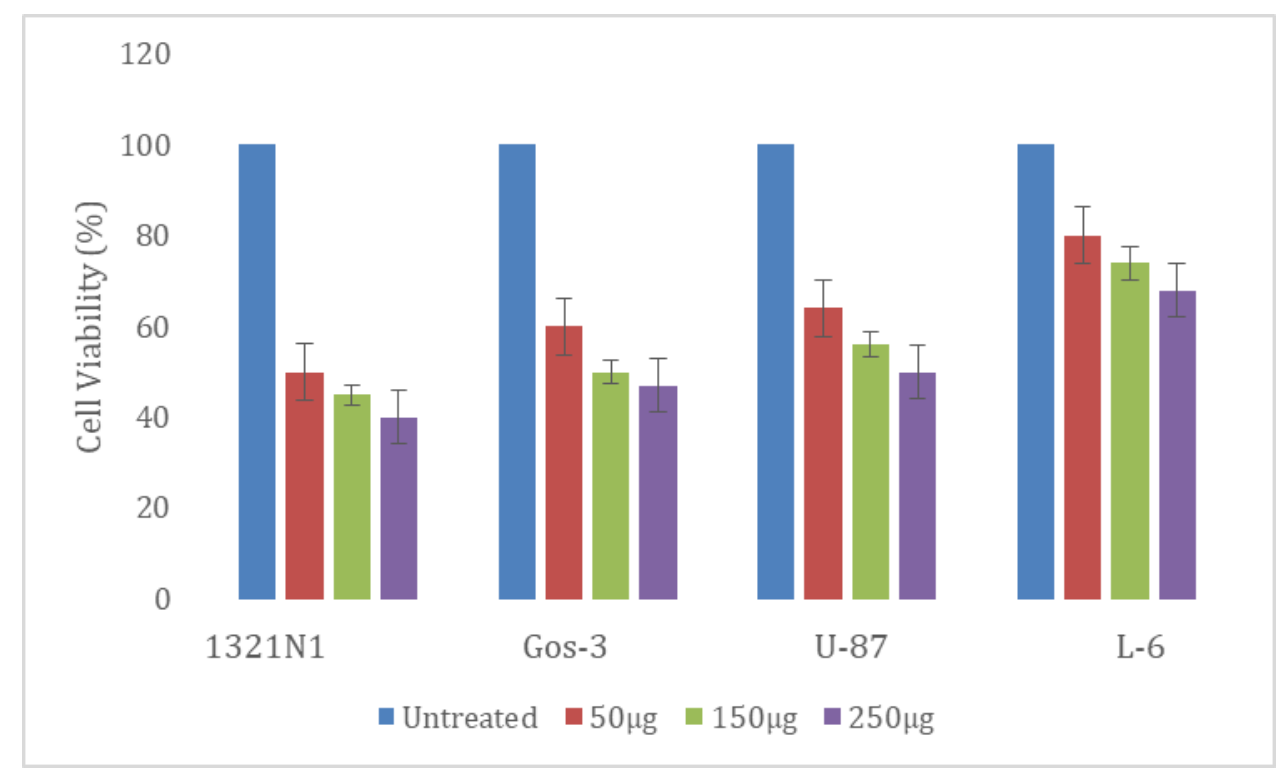

Figure 1 Dose-dependent effects of Cyclophosphamide

Figure 2 shows the effect of Cyclophosphamide $(250 \mu \mathrm{g})$ alone or the $\alpha, \beta$ momorcharin extract of $M$. charantia (1000 $\mu \mathrm{M}$, a high dose) alone or a combination of Cyclophosphamide (250 $\mu \mathrm{g})$ with the $\alpha, \beta$ momorcharin extract of $M$. charantia $(1000 \mu \mathrm{M})$ on the viability of the three different cancer cell lines and on healthy L6 skeletal muscle cell line 
employed in this study. Also shown in the figure 2 are the untreated three different cancer cell lines and healthy L6 skeletal muscle cell line for comparison. All the cells were treated with Cyclophosphamide and $\alpha, \beta$ momorcharin extract of M. charantia (drug + extract) for 24 hours. Control cell lines were also incubated for the same time. The results show that in all three different cancer cell lines (1321N1, Gos-3, U87-MG,) either Cyclophosphamide or $\alpha, \beta$ momorcharin extract of $M$. charantia can evoked marked and significant $\mathrm{p}<0.05$ decreases in the cell viability (cell death) compared to untreated cells $(100 \%$ viability). However, when Cyclophosphamide was combined with the $\alpha, \beta$ momorcharin extract of M. charantia, there was a further decrease in cell viability. These values were significantly $(\mathrm{p}<0.05)$ different compared to either untreated cell (100\%) or cell treated with either Cyclophosphamide or $\alpha, \beta$ momorcharin extract of M. charantia.

Similarly, Cyclophosphamide combined with the $\alpha, \beta$ momorcharin extract of $M$. charantia can evoke significant $(\mathrm{p}<$ 0.05 ) decrease in the death of healthy L6 skeletal muscle cell line. The results also show that combined drugs (drug + extract) were more effective in killing 1321N1, Gos-3, cell lines. It has less effective on U87-MG cell lines.

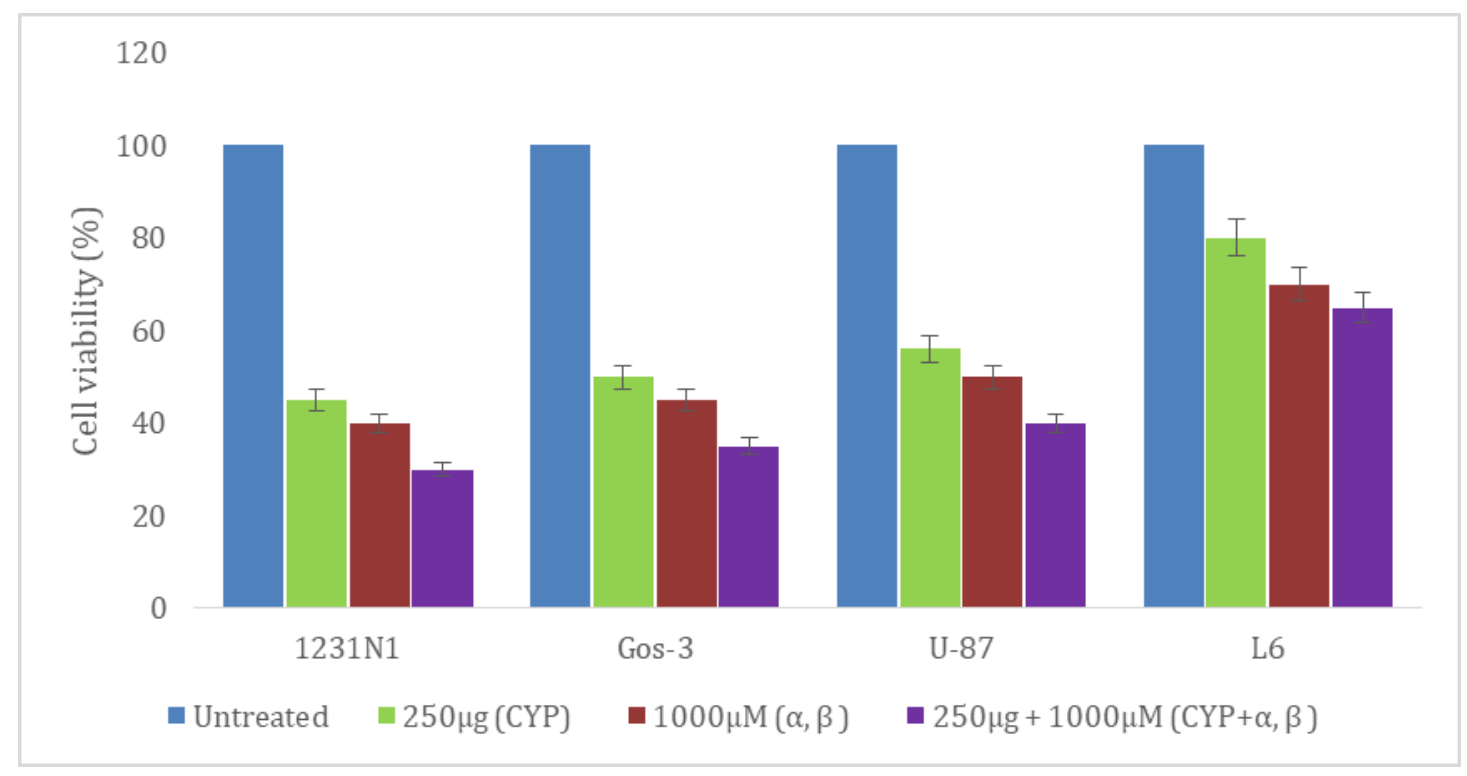

Figure 2 Effect of either of $250 \mu$ g Cyclophosphamide alone or $1000 \mu \mathrm{M}$ of $\alpha, \beta$ momorcharin of $M$. charantia alone and combination of Cyclophosphamide $(250 \mu \mathrm{g})$ with $\alpha, \beta$ momorcharin extract of $M$. charantia $(1000 \mu \mathrm{M})$ on the viability of three different cancer cell lines

This study employed the $\alpha, \beta$ momorcharin extracts of $M$. charantia, and commercially available anti-cancer drugs Cyclophosphamide to investigate their effects on the viability (cell death) of three different cancer cell lines compared to healthy L6 skeletal muscle cell line. Either the $\alpha, \beta$ momorcharin extract of $M$. charantia, Cyclophosphamide was tested alone measuring the viability of each cell line. In some experiments, Cyclophosphamide was combined with $\alpha, \beta$ momorcharin extracts of $M$. charantia, to investigate any potentiating or attenuating effect on cell viability. The rationale for this study was that M. charantia, a local plants-base (herbal) medicine could be used to treat different types of cancers. The results of the present study have shown that either Cyclophosphamide can significantly decrease the viability of 1321N1, Gos-3, U87-MG, cancer cell lines. Both anti-cancer drugs also decreased the viability of healthy L6 skeletal muscle cell line. The effect of each drug was dose-dependent with maximal effect occurring at Cyclophosphamide. The results of this study also show that combining a moderate to a high dose of Cyclophosphamide with a high dose of either the $\alpha, \beta$ momorcharin extract of $M$. charantia only produce a small, but significant decrease in the viability of each cancer cell line compared to the effect of Cyclophosphamide and the $\alpha, \beta$ momorcharin extract of $M$. charantia alone. This small decrease in cell viability of each cell line was slightly significant, but it was neither additive nor synergetic compared to the separate effect of each. This was a rather surprising result in this study.

\section{Conclusion}

In conclusion, the results of this study have clearly demonstrated that the $\alpha, \beta$ momorcharin extract of $M$. charantia can evoke significant decreases in cancer cell viability (an increase in cell death) without killing healthy cell line like L6 skeletal muscle cell line. Either Cyclophosphamide with maximal effect of Cyclophosphamide can also elicit dosedependent decreases in cancer cell viability. Combining Cyclophosphamide with either the $\alpha, \beta$ momorcharin extract of 
M. charantia had no additive or synergetic effect on the viability of each cell line compared to the effect of either alone. It is concluded that extracts of $M$. charantia possess anti-cancer properties since they can induce cell death.

\section{Compliance with ethical standards}

\section{Acknowledgments}

We gratefully acknowledge University of Central Lancashire for Science and technology for providing the financial support and required facilities to carry out this research work through a scientific research grant.

\section{Disclosure of conflict of interest}

Authors has declared that no competing interests exist.

\section{References}

[1] Ahmed I, Sharma AK, Ponery AS, Bener A, Singh J. The influence of Momordica charantia on ultrastructural abnormalities of myelinated fibres in experimental diabetes. Int. J Diabetes. 1999; 7(1): 110-121.

[2] Licastro F, Franceschi C, Barbieri L, Stirpe F. Toicity of Momordica charantia lectin and inhibitor for human normal and leukaemic lymphocytes. Virchows Arch B Cell Pathol Incl Mol Pathol. 1980; 33(6): 257-265.

[3] Zhu ZJ. Studies on the active constituents of Momordica charantia. Yao Hsueh. Hsueh. 1990; 25(3): 898-903.

[4] Tsao SW, Ng TB, Yeung HW. Toxicities of trichosanthin and alpha-momorcharin, abortifacient proteins from Chinese medicinal plants, on cultured tumor cell lines. Toxicon. 1990; 28(4): 1183-1192.

[5] Asli S, Alaattin S. Antioxidant and chemo protective properties of Momordica charantia L. (bitter melon) fruit extract. African Journal of Biotechnology. 2007; 3(6): 273-277.

[6] Manoharan G, Singh J. The Anti-Diabetic Effects of Momordica charantia: Active Constituents and Modes of Actions. The Open Medicinal Chemistry Journal. 2011; 5(6) :70-77.

[7] Manoharan G, Singh J. Effect of $\alpha, \beta$ momorcharin on viability, caspase activity, cytochrome c release and on cytosolic calcium levels in different cancer cell lines. Molecular and Cellular Biochemistry. 2014; 2(6): 4233-240.

[8] Manoharan G. Effects of $\alpha, \beta$ momorcharin extract of Momordica Charantia fruit extract with the combination of temozolamide and vinblastine in the treatment of glioma cancer In-vivo. International Journal of Pharmacy and Pharmaceutical Research, 2020, 17(3):291-301.

[9] Aoki T, Mizutani T, Ishikawa M, Sugiyama K, Hashimoto N. A first feasibility study of temozolomide for Japanese patients with recurrent anaplastic astrocytoma and glioblastoma multiforme. Int.J.Clin.Oncol. 2003; 8(6): 301304.

[10] Balow J, Hurley D, Fauci A. Cyclophosphamide suppression of established cell-mediated immunity. Quantitative vs. qualitative changes in lymphocyte populations. J Clin Invest. 1975; 56(1): 65-70.

[11] Effects of Momordica Charantia fruit extract with the combination of paclitaxel in the treatment of glioma cancer In-vivo. East African Scholars Journal of Biotechnology and Genetics, 2019, 1(11):21-24.

[12] Jin J, Chen F, Wang Q, Qiu Y, Zhao L, Guo Z. Inhibition of TNF- $\alpha$ by cyclophosphamide reduces myocardial injury after ischemia-reperfusion. Ann Thorac Cardiovasc Surg. 2013; 19(1): 24-29.

[13] First M. Immunosuppressive agents and their actions. Transplant Proc. 2002; 34(5): 1369-1371.

[14] Chen L, Waxman D. Cytochrome P450 gene-directed enzyme prodrug therapy (GDEPT) for cancer. Curr Pharm Des. 2002; (15): 1405-1416.

[15] Ortiz de Montellano P. Cytochrome P450-activated prodrugs. Future Med Chem. 2013; 5: 213-228.

[16] Espinosa E, Zamora P, Feliu J, Baron MG. Classification of anticancer drugs- a new system based on therapeutic targets. Cancer treatment Reviews. 2003; 29(11): 515-523.

[17] Schwartzbaum JA, Fisher JL, Aldape KD, Wrensch M. Epidemiology and molecular pathology of glioma. Nature Clinical Practice Neurology. 2006; 2(6): 494-503. 
[18] Fewer D, Wilson CB, Boldrey EB, Enot KJ, Powell MR. The chemotherapy of brain tumours. Clinical experience with carmustine (BCNU) and vincristine. Jama. 1972; 222(6): 549-552.

[19] Friedberg EC. How nucleotide excision repair protects against cancer. Nature Reviews Cancer. 2001; 1(6): 22-23.

[20] Tonn JC, Schachenmayr W, Kraemer HP. In vitro chemo sensitivity test of malignant gliomas: clinical relevance of test results independent of adjuvant chemotherapy. Anticancer Res. 1994; 14(6): 1371-1375.

[21] Sawyer JR, Swanson CM, Roloson GJ, Longee DC, Boop FA, Chadduck WM. Molecular cytogenetic analysis of a medulloblastoma with isochromosome 17 and double minutes. Cancer Genet.Cytogenet. 1991; 57(6): 181-186.

[22] Schwartzbaum JA, Fisher JL, Aldape KD, Wrensch M. Epidemiology and molecular pathology of glioma. Nature Clinical Practice Neurology. 2006; 2(6): 494-503.

[23] Omar S. Hypoglycemic effect of the seeds of Momordica charantia. Fitoterapia. 2007; 78(6): 46-47. 